\title{
Experimental determination of the kinetics of sorption and gas filtration in coal
}

https://doi.org/10.2478/sgem-2018-0027

received August 9, 2018; accepted October 12, 2018.

Abstract: The paper presents tests set-ups for experiments on sorption kinetics and gas filtration kinetics in a porous medium. It was observed that two phenomena occur in these processes: transportation of gas into the porous solid and settling of gas molecules on the walls of the solid or within its volume. An experiment was carried out in which a thin resistance thermometer was quickly taken out of an argon stream and placed in carbon dioxide or the other way round. The measurement made it possible to determine the sorption time constant. It was demonstrated that the sorption rate is much higher than the filtration rate. Thus, filtration is the process describing the rate at which gas molecules penetrating the porous substance are adsorbed or desorbed. The sorption time constant is not $>50 \mathrm{~m}$.

In the second experiment, the author determined the rate at which gas is liberated from coal grains. The measurement method was based on measurement of the pressure of desorbing gas in constant volume. The experiment involved measurement of the pressure of the gas liberated from the coal grains in a closed chamber. The kinetic curves obtained in this way were used to determine the carbon dioxide coefficient in coal grains. During the experiment, particular focus was put on the initial stage of gas liberation (up to $0.4 \mathrm{~s}$ ).

The slower process of gas transporting in the porous structure of coal is the transporting of gas through a coal briquette. Experimentally implemented variety of boundary conditions allowed for a more complete verification of the assumed theoretical model and possibly for the exact determination of filtration parameters. The experimental set-up built for this purpose, allows for pressure and temperature measurement on the briquette side surface.

*Corresponding author: Marek Gawor, The Strata Mechanics Research Institute of the Polish Academy of Sciences, Cracow, Poland, E-mail: gawor@img-pan.krakow.pl
Keywords: sorption; filtration; sorption kinetics; filtration kinetics.

\section{Introduction}

When considering the concept of sorption kinetics in a porous solid, it should be noted that in this process, we deal with two phenomena: transport of gas into the interior of the porous substance and settling of gas molecules on the surface or within the volume of a solid. Furthermore, in this paper, sorption is understood as all phenomena associated with adsorption or desorption of gas on the surface of a solid. Adsorption is understood as the concentration of a substance on the surface or in the pore volume of a solid due to attracting surface forces. The physical interaction between atoms or gas molecules and the atoms of carbon surface is associated with the existence of attractive van der Waals' forces and repulsive forces that arise when the gas atoms approach the atoms of the solid so much that their electron shells begin to penetrate each other (short-range forces).

The gas molecule at a certain volume has three degrees of freedom in the translational movement (neglecting oscillatory and rotational movements). After this molecule is adsorbed by a solid, the number of these degrees of freedom is reduced by at least one. The adsorbed molecule can move on the surface of a solid, or it can be trapped in one place, at the bottom of the interaction potential. So the kinetics of the adsorption process can be understood as the rate of gas molecule transition from the 'free' state to the 'bonded' state. This process is also referred to as the sorption process on the free surface of a solid [1-3].

The sorption process described above takes place when the sorbent gas molecule has already reached the surface of the solid and there is an interaction of sorption forces between this molecule and the atoms of the solid. In the case of porous media, in order for the molecule to be adsorbed within the porous structure, it must enter the interior of the grain through a comparatively developed pore system [4]. The process of gas transport to the inside of the grain, which takes place due to the occurrence of 
gas pressure gradient (density, concentration), is called filtration [5]. Both processes, sorption and filtration, occur at a certain rate. It has been shown that the rate of the sorption process is much greater than the rate of filtration. Therefore, filtration is a process that determines the rate at which the gas molecules that penetrate into the interior of the porous substance become adsorbed or desorbed.

A special case in which the speed of the sorption process may be important is crushing of coal. During comminution, 'new surfaces' appear, from which the gas is released in a non-filtration manner. Crushing of coal can occur during mining operations [6], sudden rock bursts or outbursts [7, 8]. In recent years, the hazards of ejection phenomena occur not only in coal mines, but also in copper ore mines [9-11]. In the literature [12-14], the term sorption kinetics is often understood as the rate of filtration processes occurring in porous media. In the further part of the study, the author presents an exact determination of the kinetics of the sorption and filtration processes and an attempt to determine the rate of these processes.

The inability to follow the kinetic process in short time intervals and in the initial period of the sorption process is an important issue. The author presents a method for measuring the kinetics of the gas liberated from coal grains. This method is characterised by the fact that it is possible to make measurements in non-stationary states. It makes it possible to make the first measurement of the gas release $0.1 \mathrm{~ms}$ after the pressure change.

\section{Determination of the time constant of gas sorption on hard coal}

The basic assumption during the theoretical consideration of the sorption kinetics made in this section is the adoption of sorption without filtration effects. Thermal effects that constitute the basis for inferring the rate of the sorption process are related to the energy of interaction of the gas molecule with the solid surface [15]. If the gas molecule is adsorbed on the surface of a solid, the sorbent heat $Q_{s}$ is immediately released. During desorption, heat is taken from the environment and the coal skeleton, which is why the coal is cooled down [16]. As a result, we assume that the rate of heat release during sorption processes is a measure of the speed of the sorption process itself. Thus, by measuring the temperature changes during the process, we can determine the time constant of sorption $\tau_{s}$. Even if we assume that the gas molecules are transported through the pores of the coal, due to the fact that the thermal effects are not associated with the gas transport, it can be assumed that the above-described method of measuring the sorption time constant does not depend on the size of the grains used in the experiment [17].

\subsection{Set-up for measuring time constant}

To measure the temperature changes during sorption and desorption of carbon dioxide on hard coal, resistive thermometers were used. A sensor was made from platinum-rhodium (PtRh) with the initial diameter wire of $10 \mu \mathrm{m}$ diameter. By flattening the wire, the author obtained sensors with thicknesses in the range of $1.0-1.3 \mu \mathrm{m}$. Subsequently, the thermometer was covered with coal grains of size 4-26 $\mu \mathrm{m}$. In order to ensure better thermal contact and mechanical bonding to the thermometer, these grains were glued to it with a nitrocellulose lacquer. The time constant of resistance thermometers is $\sim 5 \mathrm{~ms}$.

Two thin-walled steel tubes were soldered, and their internal walls were sawed (Fig. 1). It allowed for the insertion of the thermometer inside the tube and its transfer from one tube to the other. On one of the tubes, a radiator was wound, which made it possible to heat the gas flowing through the pipe by several degrees. The radiator was used to equalise the temperatures in the streams of gases flowing through both tubes, as well as to measure the time constant of thermometers.

The thermometer with the glued coal was attached to the cross-table, so that it could be quickly moved from the initial position in the axis of one of the tubes to the axis of the other tube. The time of moving the thermometer measured using appropriately set contacts was $\sim 20 \mathrm{~ms}$.

For the experiment, carbon dioxide and argon were selected ( $\mathrm{CO}_{2}$ as the gas sorbed on coal). These gases have similar molecular weights of 44 and 40, respectively. Argon sorption on hard coal was found to be low compared to the sorption of carbon dioxide. The gas from the bottle flowed through a reducer and a copper coil placed in water, and then, it flowed into the atmosphere through a steel tube. The usage/flow rate of both gases was measured using liquid manometers with a sloping tube $\left(M_{1}, M_{2}\right)$. The gas usage/flow rate was selected so that the temperature in the streams was the same.

After the thermometer with coal was placed in carbon dioxide, the adsorption process started [18]. As a result of the release of sorption heat, the coal was heated up and, at the same time, it was cooled down by the gas stream. The temperature rose to a certain value and then decreased to the initial value.

When the thermometer with the coal was moved in the opposite direction from carbon dioxide to argon, 


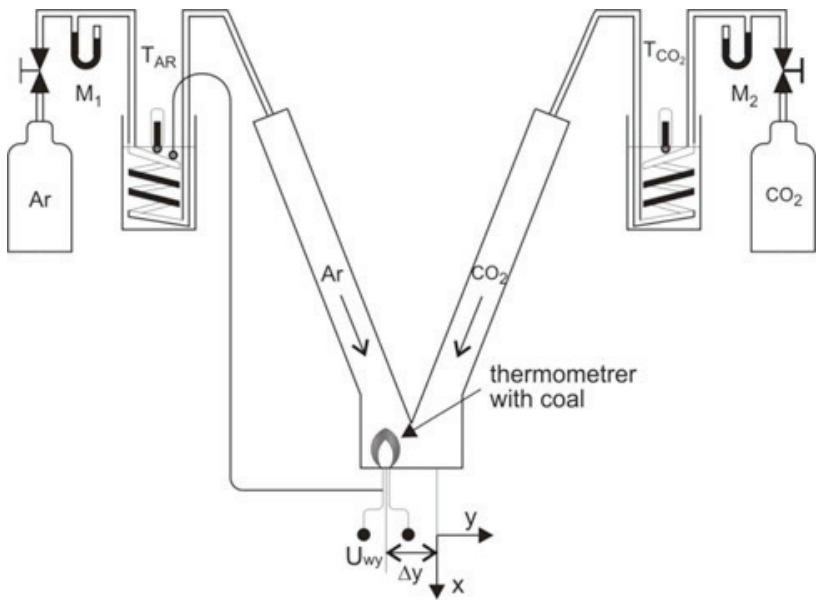

Figure 1: The principle of measuring the sorption time constant (Gawor and Skoczylas 2014).

the temperature changes took the opposite sign. During desorption, the coal cooled down, and then its temperature increased to its initial value.

\subsection{Results of measurements of the sorption time constant}

The solution of the thermal conductivity equation with gas sorption as the source is the following function:

$$
T(t)=A \exp \left(-\frac{t}{\tau_{s}}\right)+B \exp \left(-\frac{t}{\tau_{t}}\right)+T_{k}
$$

where $\tau_{s}$ is the time constant of sorption; $\tau_{t}$ is the time constant for temperature equalisation; and $A, B$ and $T_{k}$ are constants.

As the above formula shows, in the experiment, there are two opposing processes with different time constants. During adsorption, due to heat release, the thermometer is heated together with the coal. The time constant of this process is $\tau_{s}$. At the same time, due to the temperature difference between the gas stream and the thermometer with coal, temperature equalisation occurs. The time constant of this process is $\tau_{t}$.

Fig. 2 shows the temperature changes recorded when transferring the thermometer with coal from argon stream to the carbon dioxide stream (adsorption), and vice versa - from the carbon dioxide stream to the argon stream (desorption). These charts show the theoretical curve, adjusted to experimental data, which was used to determine the constants of sorption time and constants of temperature equalisation. Such charts, obtained in the

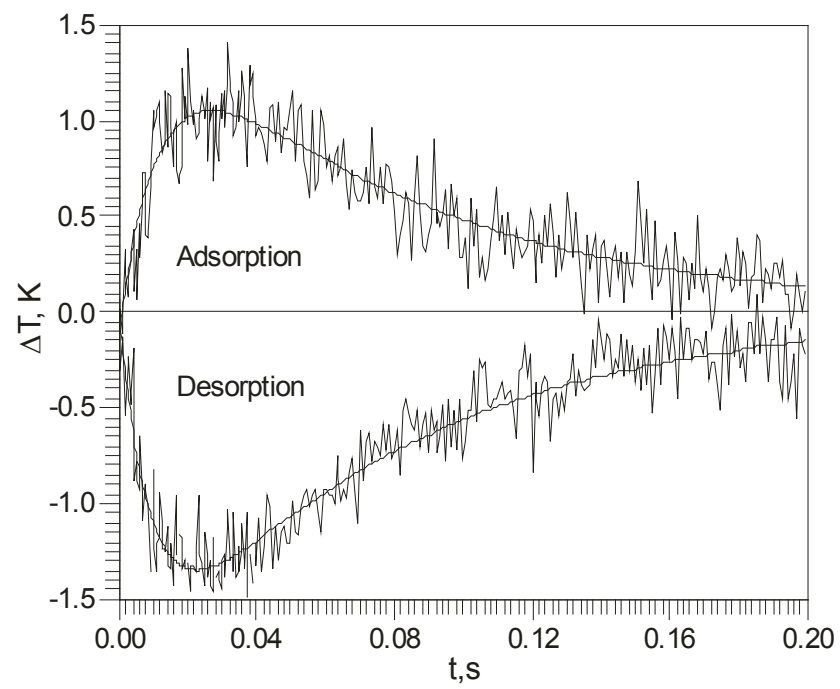

Figure 2: Temperature change when measuring the adsorption and $\mathrm{CO}_{2}$ desorption time constant.

experiments, were the bases for the determination of the sorption time constant.

The lowest sorption time constant $(10 \mathrm{~ms})$ was obtained for a $1.3-\mu \mathrm{m}$-thick resistance thermometer and a thickens of coal $6.5 \mu \mathrm{m}$. However, with very thin coal layers, the temperature changes are not very high, and therefore, the sorption time constant may be determined with high measurement uncertainty. In most experiments, this constant was $\sim 50 \mathrm{~ms}$. Therefore, it can be concluded that the sorption time constant is not greater than $50 \mathrm{~ms}$. The sorption process itself is therefore a very fast process.

\section{Gas filtration in coal grains}

The principle of the method of measurement of the gas released from coal grains is based on the measurement of the desorbing gas pressure at a constant volume. The kinetic curves obtained by this method were used to determine the carbon dioxide filtration coefficient in coal grains. In order to study the desorption kinetics with particular regard to the initial stage of the process, coal of a given grain size was closed in a sealed cell, de-gassed and then saturated with gas under a given pressure. Then, the partition separating the gas-saturated coal from the chamber with a much larger volume, in which the initial pressure was close to zero, was removed. As a result of the lowering of the external pressure, the free gas between the grains and in the macropores expanded. Desorption of the bound gas occurred, and the gas flowed out of the grain. Pressure in the chamber increased, which was a measure of the amount of gas released. In order to 


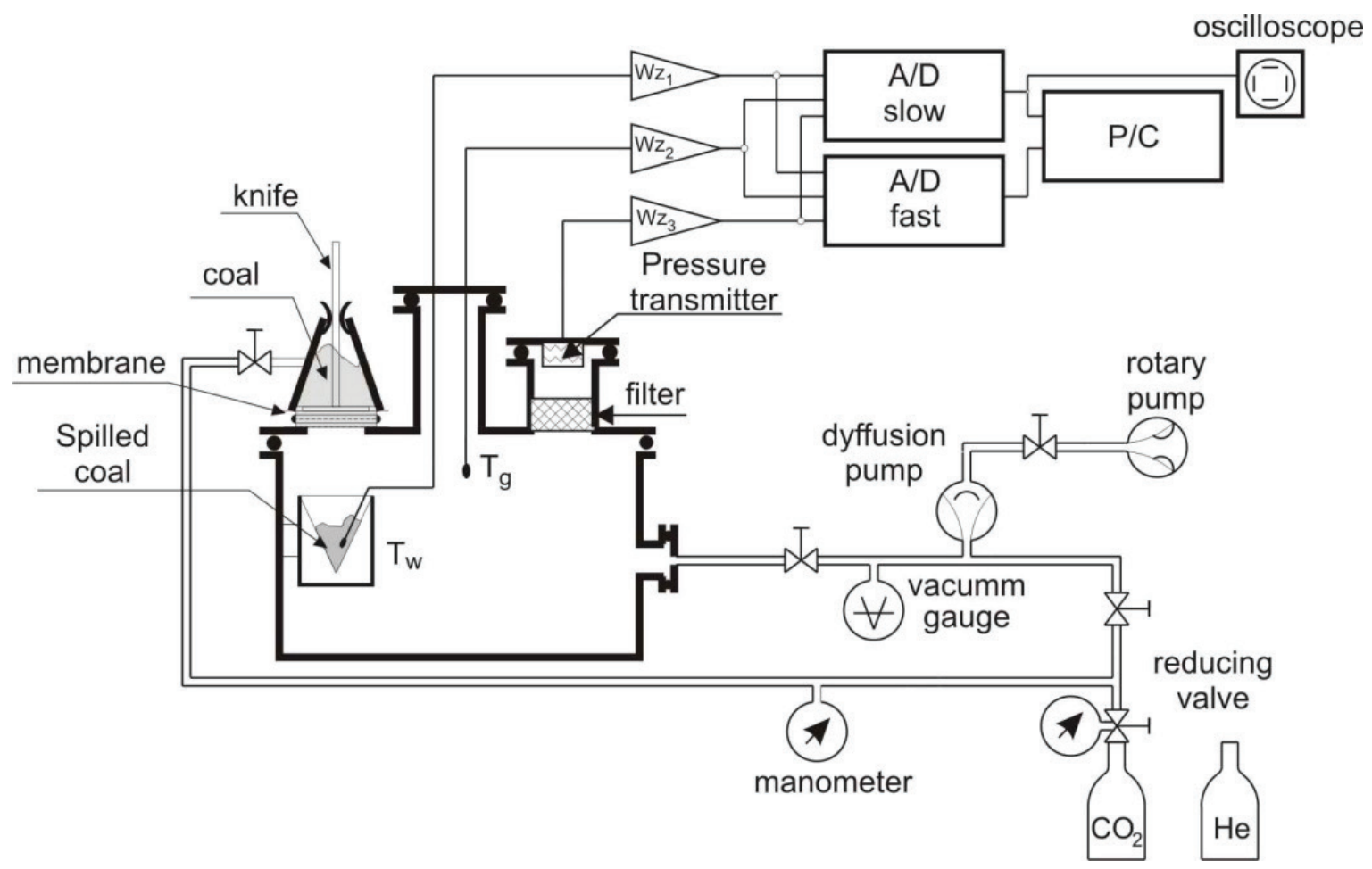

Figure 3: Scheme of the setup for testing the gas filtration coefficient in coal grains.

determine the amount of gas between the coal grains, the coal was saturated with a noble gas - helium. It was assumed that, in these experiments, only the free gas is responsible for the increase in pressure in the chamber. In order to determine the amount of released gas, the pressure measured in helium experiments was subtracted from the pressure obtained in experiments with carbon dioxide. In the experiments, the coal temperature during the process of desorption of the sorbed carbon dioxide was also measured.

\subsection{Description of the measurement set-up}

The scheme of the experiment is shown in Fig. 3. Experiments were carried out at an initial gas pressure of $0.25 \mathrm{MPa}$. During the experiments, it was assumed that desorption would occur at a relatively low final pressure, i.e. around $30 \mathrm{~Pa}$.

The large chamber was connected by a valve with a vacuum system. This connection made it possible to de-gas the chamber to $1 \mathrm{~Pa}$. The coal was saturated with gases $\left(\mathrm{CO}_{2}, \mathrm{He}\right)$ that flowed from a cylinder connected to the pneumatic system through a pressure-reducing valve. Gas pressure measurement was made through a precise pressure gauge. The valve system made it possible to de-gas the coal and then saturate it with a selected gas.
In the top cover of the chamber, there were sockets in which were placed the following:

1 a cell with carbon,

2. a cover with thermocouple connections and

3. a cover with a pressure transmitter.

In the chamber, there was a vessel, where coal spilt after 'destruction' of the closing partition of the cell. The vessel was set directly under the cell with carbon. Inside the vessel, there was a thermocouple $T_{w}$ measuring the temperature of coal during gas release. The thermocouple measuring the gas temperature $T_{g}$ was placed in the chamber at the height of the membrane separating the chambers. The pressure transmitter lay slightly above the partition. In order to protect it from contamination by coal dust, it was separated from the large chamber by a filter. The cell with coal was mounted on the top cover of the large chamber, in a socket sealed with rubber gaskets.

There was a rod in the axis of the cell. Its one end protruded outwards and the other end ended with a knife and rested on the membrane. The dislocation of the rod caused the diaphragm to rupture, pouring coal into a large chamber. To measure the gas pressure, a piezoresistive pressure sensor was used (sensor with a silicon diaphragm with vaporised strain gauge bridge). The changes in coal and gas temperatures were measured using specially 
made thermocouples from constantan-manganese wire with thickness of $\sim 3 \mu \mathrm{m}$ and sensitivity of $40 \mu \mathrm{V} / \mathrm{K}$.

Voltage signals were recorded by two analogue-todigital cards, namely 'fast' and 'slow'. Such a solution makes it possible to register voltages in a large range of time. One of the cards recorded the voltage from the pressure sensor in the time range of up to $0.4 \mathrm{~s}$, and the other recorded the same for much longer time periods, i.e. up to $100 \mathrm{~min}$.

The coal was pre-crushed using a laboratory stirrer and then milled in an impact mill to obtain very fine grains. The following grain classes were selected: $25-32$, 63-71, 90-100 and 200-250 $\mu \mathrm{m}$.

In further considerations, we assume that the permeability coefficient $k$ is constant, and that it does not depend on the radius or time.

We assume that the equation of motion is in the form of the Darcy equation, gas is a perfect gas and the sorption isotherm is linear (Henry's law). By introducing dimensionless gas density, as in Equation (2), we get Equation (3) [20].

$$
\xi(r, t)=\frac{\rho_{g}(r, t)}{\rho_{\max }}
$$

where $\rho_{\max }$ is the maximum initial gas density;

$$
\frac{\partial \xi}{\partial t}=D \nabla^{2} \xi^{2}
$$

where $D$ is filtration coefficient, and

$$
D=\frac{k C \rho_{\max }}{2(H C+\psi)}
$$

It is a non-linear filtration equation. The above equation will be considered in the spherical coordinate system. According to the experimental conditions, this equation should be solved with the following initial boundary conditions:

$$
\begin{aligned}
& \rho_{g}(r, 0)=\rho_{\max } \quad \xi(r, 0)=1 \quad 0 \leq r \leq r_{0} \\
& \rho_{g}\left(r_{0}, t\right)=0 \quad \xi\left(r_{0}, t\right)=0 \quad t \geq 0 \\
& \frac{\partial \rho_{g}}{\partial r}=0 \quad \frac{\partial \xi}{\partial r}=0 \quad t \geq 0, r=0
\end{aligned}
$$

The first condition means that at the initial moment inside the grain, the density of free gas is as shown in Equation (6):

$$
\rho_{\max }=\frac{p_{0}}{C}
$$

where: $\psi$ is the porosity, $H$ is the Henry's constant, $p_{0}$ is the pressure of the gas that saturates the coal, $C=1 / \mathrm{RT}$, $\mathrm{R}$ is the universal gas constant and $\mathrm{T}$ is the absolute temperature.

The second condition means that on the outside of the grain, the density of the gas is equal to zero (the seeds are in the chamber where the pressure is $\sim 1 \mathrm{~Pa}$ ). The third condition is a condition for the symmetry of the density distribution of the free gas relative to the centre of the coal grain.

Fig. 4 shows the relationship between pressure and time in the large chamber in the case of the experiments wwith carbon dioxide and helium. Grains of size 25-32 $\mu \mathrm{m}$ were used in the experiment. The pressure of saturation with both helium and carbon dioxide was 0.25 MPa. From these graphs, it can be seen that for a period of $\sim 10 \mathrm{~ms}$, the pressures of $\mathrm{CO}_{2}$ and helium increase equally. Next, the increase in helium pressure is stopped, and after $15 \mathrm{~ms}$, it settles. This character of pressure change of helium released from coal confirms the assumption that the gas is non-sorbable on coal. Fig. 5 shows the amount of desorbed $\mathrm{CO}_{2}$ in the initial desorption period. After $0.4 \mathrm{~s}$, a relatively large amount of gas is released from the grains.

The total amount of gas released is shown in Fig. 6. The dotted curve shows the calculated theoretical amounts of the released gas.

\section{Non-stationary gas filtration in coal briquettes}

Turning to slower gas transport processes in the porous structure of coal, this section presents the results of experimental gas filtration through a coal briquette. A theoretical description of this phenomenon is also presented. The experimentally implemented variety of boundary conditions allowed for a relatively complete verification of the assumed theoretical model and, possibly, for the exact determination of filtration parameters [21]. 


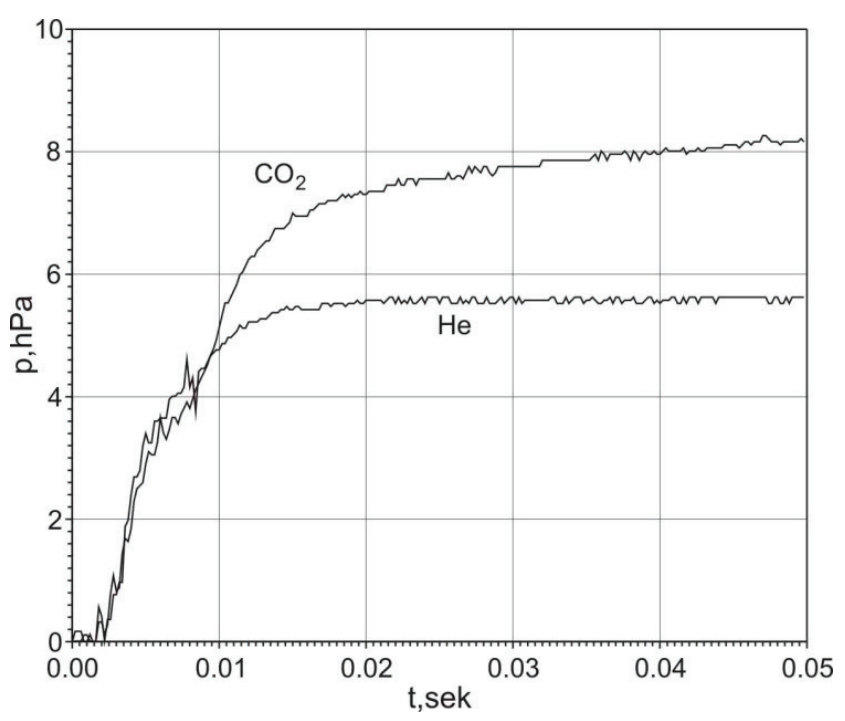

Figure 4: The relationship between pressure and time in the initial desorption period of $\mathrm{CO}_{2}$ and $\mathrm{He}$; grains $25-32 \mu \mathrm{m}$.

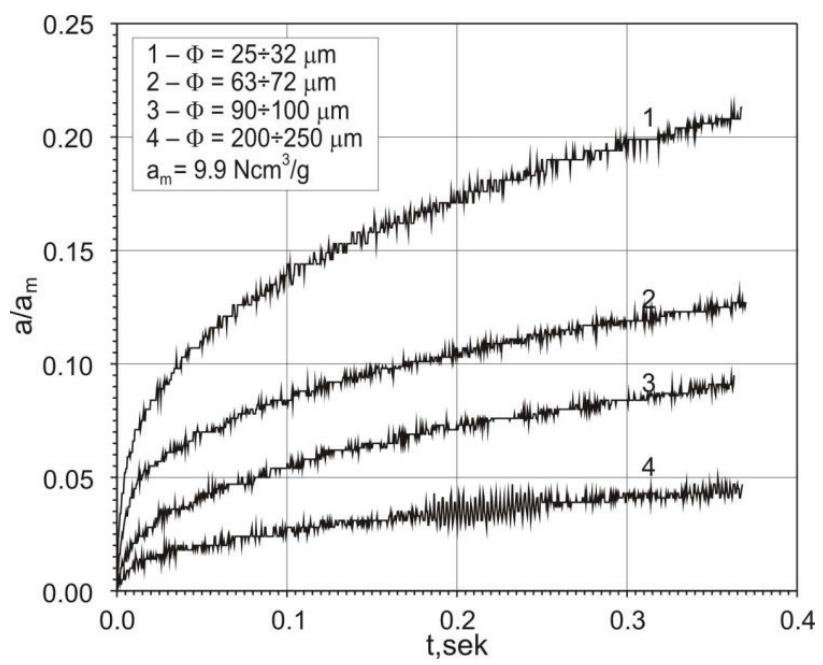

Figure 5: Amount of desorbed $\mathrm{CO}_{2}$ in the initial desorption period, $p_{0}=0.25 \mathrm{MPa}$.

\subsection{Measuring set-up for testing gas filtration in briquettes}

To understand the filtration and sorption processes accompanying the propagation of pressure waves in coal that is saturated with gas, it is necessary to measure the time and space distributions of the physical quantities that determine the course of the phenomenon. A set-up created especially for this purpose (Fig. 7) (its detailed description is presented in a previous paper [22]) makes it possible to measure the pressure in the macropores of coal samples and the temperature of its skeleton. Test samples in the form of specially prepared briquettes (B) were

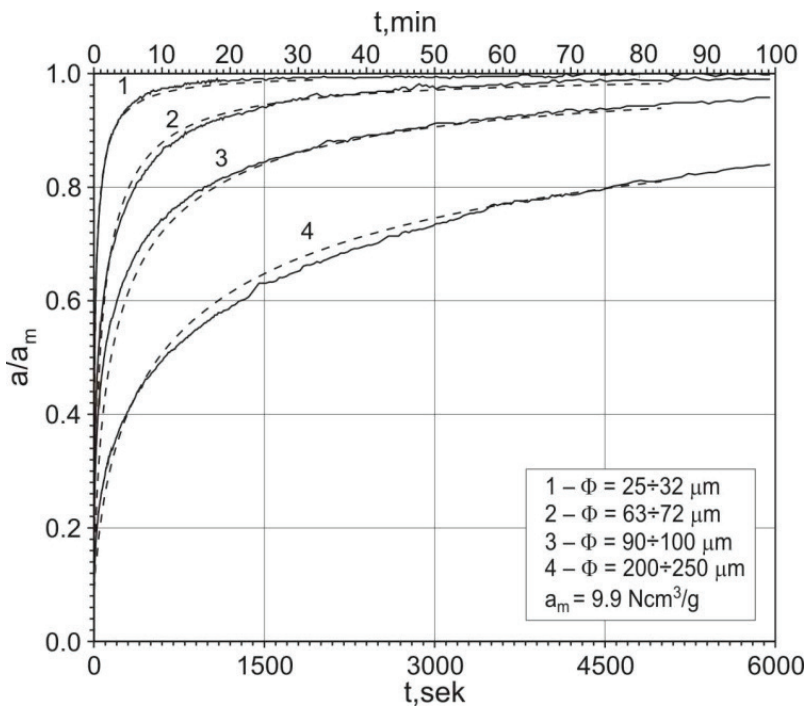

Figure 6: Amount of desorbed $\mathrm{CO}_{2}$ in time, $\mathrm{p}_{0}=0.25 \mathrm{MPa}$.

formed in a briquetting machine using a hand-operated screw press.

The sidewalls of the briquetting machine had sockets in which pressure transducers $P_{i}$ and conduits for the assembly of thermocouples $T_{i}$ were mounted. The thermocouples were put inside the briquette during its formation process (pressing).

A system of joints and valves connected the briquetting machine with the pneumatic system. The pneumatic system consisted of a rotary vacuum pump $P R$, a gas cylinder with a manostat $\left(\mathrm{CO}_{2}, \mathrm{He}\right)$ and an electropneumatic pressure transmitter PEP.

The transmitter, controlled by the voltage generator (G), made it possible to set periodically changing gas pressure at the front of the briquette [23]. The pneumatic system made it possible to saturate the briquette with gas or empty it by implementing various pressure conditions on the edges of the briquette. The saturation pressure was measured by a precise manometer $\mathrm{M}$.

Electrical signals from the pressure and temperature transmitters were fed to amplifiers $\mathrm{AP}$ and $\mathrm{AT}$ and then recorded by analogue-to-digital $(\mathrm{A} / \mathrm{C})$ cards. The analogue-to-digital card allowed for recording signals in a digital form in a computer PC.

The card was controlled by a software that was specially developed for this experiment. It enabled setting the following parameters: the sampling rate, the recording time and the number of voltage signals recorded. Recorded voltages, through relevant characteristics, were converted into pressure and temperature values. During the experiment, the current pressure and temperature values were measured on the monitor screen. After the 


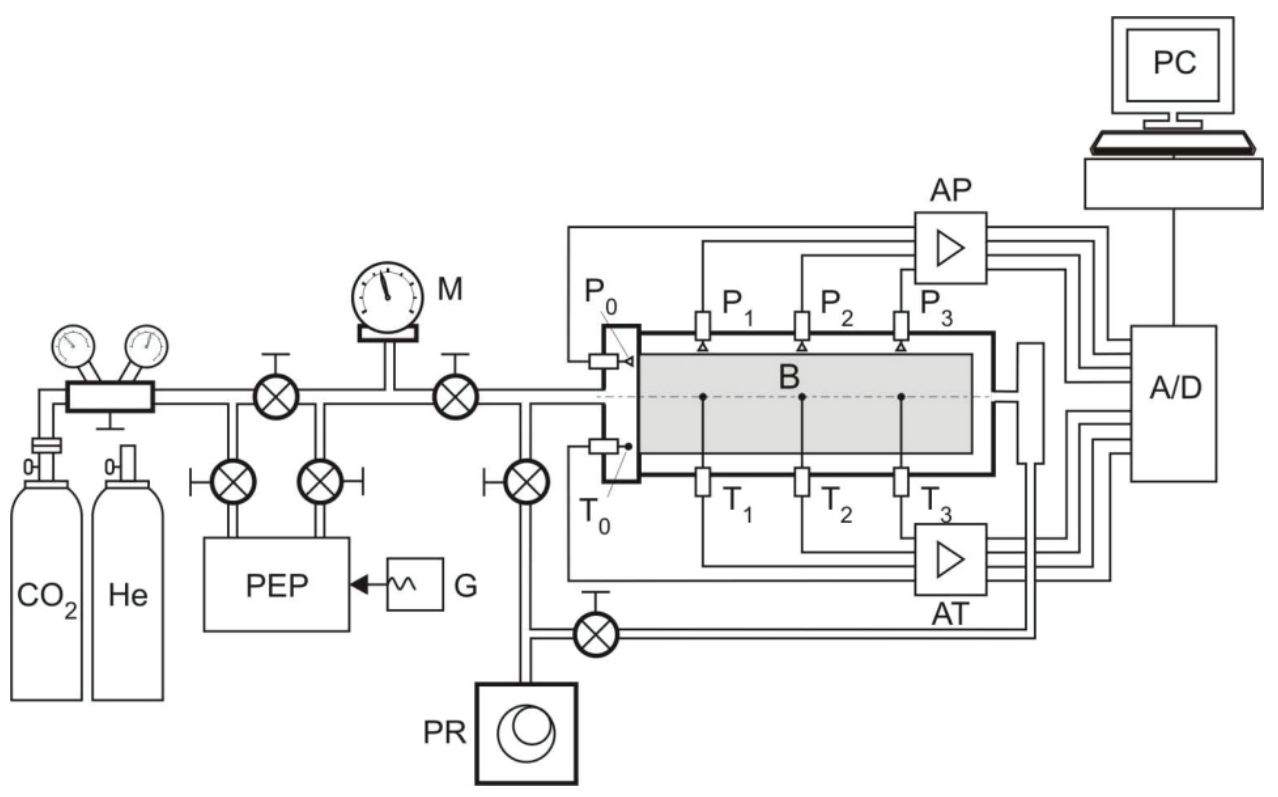

Figure 7: Scheme of the measurement station for determining the gas filtration coefficient in coal briquettes.

experiment, the time of the next measurement and the values of measured pressures and temperatures were saved in a text file.

\subsection{The results of gas filtration experiments in briquettes}

The presented set-up was used to produce the following boundary and initial conditions in the briquette:

1. positive pressure jump at the front of the briquette, the bottom of the briquette closed - saturation of the briquette with gas;

2. negative pressure jump at the front of the briquette, the bottom of the briquette closed - de-gassing the briquette;

3. constant pressure at the front of the briquette, bottom of the briquette open to vacuum;

4. constant pressure at the front of the briquette, bottom of the briquette open to the atmosphere;

5. periodically changing pressure at the front of the briquette, as shown in Equation (7), the briquette bottom closed.

$$
p=p_{0}+p_{1} \sin (\omega t)
$$

The positive pressure jump in the briquette was triggered by manually opening the valve between the briquette front and the cylinder filled with gas up to the pressure $p_{o}$. Examples of the changes in pressure over time are shown in Fig. 8. Before the experiment, the briquette was de-gassed. The time of the pressure rise in the chamber in front of the briquette, measured by a pressure gauge $p_{0}$, was of the order of $0.1 \mathrm{~s}$. The negative pressure jump was triggered by opening the valve between the front of the gas-saturated briquette and a large tank connected to the vacuum pump. The applied saturation pressures ranged from 0.3 to $0.45 \mathrm{MPa}$. Examples of changes in pressure over time are shown in Fig. 9.

The sinusoidal, changing pressure at the front of the briquette was obtained by joining the front of the briquette with an electro-pneumatic converter. The converter was controlled by an voltage generator (G). The sinusoidal changing pressure had a frequency from 0.05 to $0.0005 \mathrm{~Hz}$ and an amplitude of $\sim 0.05 \mathrm{MPa}$. The values of the constant component were $\sim 0.16 \mathrm{MPa}$. The time of settling the pressure courses in the briquette depended on the frequency and type of gas and varied from several to several dozen minutes.

When implementing the boundary conditions in condition 3, the briquette was first fully de-gassed. De-gassing was carried out from the front and bottom of the briquette simultaneously. Then, after closing the valve connecting the briquette face with the pump, de-gassing of the briquette from the bottom continued, and at the briquette front, a positive pressure jump up to the value $p_{o}$ was applied. The experiments with the boundary condition in condition 4 were carried out in a similar way. The difference was that the bottom of the briquette was opened to atmospheric pressure. In the case 


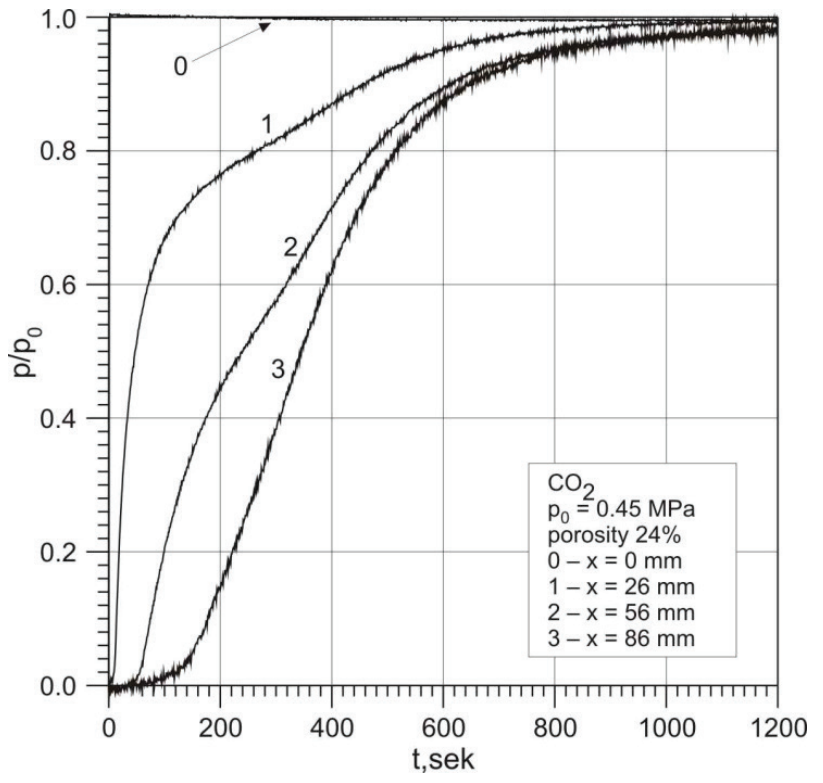

Figure 8: Saturation of the briquette with carbon dioxide - the bottom of the briquette is closed.

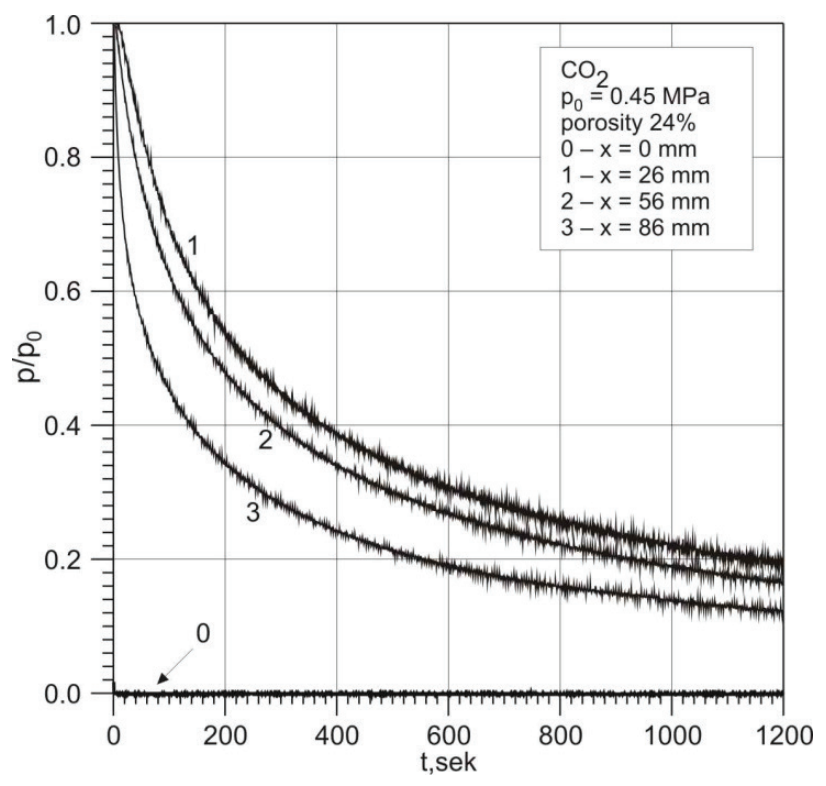

Figure 9: Removing carbon dioxide from briquettes - the bottom of the briquette is closed.

of the boundary condition in condition 5 , the pressure at the front of the briquette was applied using an electropneumatic transmitter.

\section{Conclusions}

The literature review reveals that the majority of papers do not distinguish between the kinetics of sorption and filtration in hard coal. In almost all experimental papers, the term sorption kinetics is understood as the rate at which gas penetrates the porous structure of coal. However, from the physical point of view, sorption and filtration are completely different processes. Only in theoretical considerations models are designed to determine the kinetics of sorption.

The conducted experiments lead to the conclusion that the sorption time constant is not more than $50 \mathrm{~ms}$. This estimation is quite formal, because in the experiments, transport processes were not completely eliminated.

When determining the time constant of sorption, coal layers of a few micrometers were used. On the one hand, it resulted in the elimination of the filtration process, but on the other hand, it caused a decrease in the temperature signal and increased the measurement uncertainty.

The basic conclusion that can be derived from the experiments is that the sorption process of gases on hard coal is much faster than gas transport into the pore structure of coal. Consequently, in the theoretical considerations concerning the kinetics of gas penetration through coal, the elements related to gas sorption may be omitted.

\section{References}

[1] Wierzbicki, M., Skoczylas, N., Kudasik, M. (2017). Use of a unipore diffusion model to describe the kinetics of methane release from coal spoil in the longwall environment. Studia Geotechnica et Mechanica, 39(2), 81-89.

[2] Skoczylas, N., Topolnicki, J. (2016). The coal-gas system - the effective diffusion coefficient. International Journal of Oil Gas and Coal Technology, 12(4), 412-424.

[3] Sevenster, P.G. (1959). Diffusion of gases through coal. Fuel, 38, 403-418.

[4] Kudasik, M., Skoczylas, N. (2017). Analyzer for measuring gas contained in the pore space of rocks. Measurement Science and Technology, 28, 10.

[5] Skoczylas, N. (2015). Determining the gas permeability coefficient of a porous medium by means of the bubblecounting flow meter. Measurement Science and Technology, 26(8).

[6] Młynarczuk, M., Habrat, M., Skoczylas, N. (2016). The application of the automatic search for visually similar geological layers in a borehole in introscopic camera recordings. Measurement, 85, 142-151.

[7] Wierzbicki, M., Skoczylas, N. (2014). The outburst risk as a function of the methane capacity and firmness of a coal seam. Archives of Mining Sciences, 59(4), 1023-1031.

[8] Dziurzyński, W., Krach, A. (2002). Mathematical model of mine ventilation process interrupted by a rock burst. Archives of Mining Sciences, 47, 333-346. 
[9] Pajdak, A., Kudasik, M. (2017). Structural and textural characteristics of selected copper-bearing rocks as one of the elements aiding in the assessment of gasogeodynamic hazard. Studia Geotechnica et Mechanica, 39(2), 51-59.

[10] Pajdak, A., Godyn, K., Kudasik, M., Murzyn, T. (2017). The use of selected research methods to describe the pore space of dolomite from copper ore mine, Poland. Environmental Earth Sciences, 76(11), 389.

[11] Wierzbicki, M., Mtynarczuk, M. (2013). Structural aspects of gas and dolomite outburst in Rudna copper mine, Poland. International Journal of Rock Mechanics \& Mining Sciences, 57, 113-118.

[12] Kawęcka, J. (1988). Kinetyka sorpcji i dyfuzji. Zeszyty Naukowe AGH. Chemia, 8, 115-142.

[13] Éttinger, I.L., Rabczenko, S.A. (1988). Metanoperenos v obrazcachugla i ugolnychplastach. ChimijaTverdogoTopliva, 4, 29-34.

[14] Korta, A., red. (1990). Badania energii i szybkości desorpcji na węglach wyrzutowych i niewyrzutowych. IMG PAN (Sprawozdanie z prac w problemie CPBP 03.06. Górotwór jako ośrodek wielofazowy), Kraków.

[15] Siricar, S. (1981). On the measurement of sorption kinetics by differential test: effect of the heat of sorption. Carbon, 19, 285-288.

[16] Timofiejew, D.P. (1967). Adsorptionskinetik (ttum. z ros). Lipsk: VEB.

[17] Skoczylas, N., Kudasik, M., Topolnicki, J. (2018). Model studies on saturation of a coal sorbent with gas taking into account the geometry of spatial grains. Przemysl chemiczny, 97(2), 272-276.

[18] Kudasik, M., Skoczylas, N., Pajdak A. (2017). The repeatability of sorption processes occurring in the coal-methane system during multiple measurement series. Energies, 10(5), 661.

[19] Gawor, M., Skoczylas, N. (2014). Sorption rate of carbon dioxide on coal. Transport in Porous Media, 101(2), 269-279.

[20] Kidder, R. E., La Habra (1957). Unsteady flow of gas through a semi-infinite porous medium. Journal of Applied Mechanics, 24, 329-332.

[21] Gawor, M. (1993). Sorpcja i dyfuzja gazów w węglu kamiennym. Archives of Mining Sciences, 38, 217-261.

[22] Gawor, M. (2004). Wyrzuty węgla i gazu w aspekcie badań eksperymentalnych zjawisk gazodynamicznych w brykietach węglowych nasyconych gazem. Prace IMG PAN. Rozprawy i Monografie nr 7. Kraków 2004. 163.

[23] Kudasik, M., Skoczylas, N., Sobczyk, J., Topolnicki, J (2010) Manostat-an accurate gas pressure regulator. Measurement Science and Technology, 21(8). 